\section{Military Technical College Kobry El-Kobbah, Cairo, Egypt}

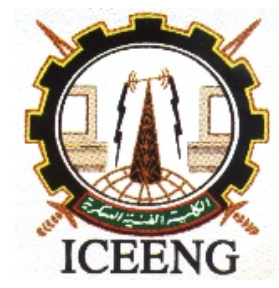

\author{
$8^{\text {th }}$ International Conference \\ on Electrical Engineering \\ ICEENG 2012
}

\title{
Phasor measurement units for out of step detection
}

\author{
By
}

\author{
Almoataz Y. Abdelaziz* \\ Amr M. Ibrahim* \\ Zeinab G. Hasan*
}

\section{Abstract:}

Synchronized phasor measurements have become an important technology with several international manufacturers offering commercial phasor measurement units (PMUs) which meet the prevailing industry standard for synchrophasors. With the occurrence of major blackouts in many power systems around the world, the value of data provided by PMUs has been recognized, and installation of PMUs on power transmission networks of most major power systems has become an important current activity.

This paper presents a transmission line protection scheme based on synchronized phasor measurement units to detect (predict) out of step condition using equal-area criterion which is consistent with transient energy function method for single machine-infinite bus system or two machines system. This scheme uses the measured values of voltages and currents, as complex values, at the generator bus and at the infinite bus. These values of voltage and current are measured in time domain and transformed into phasor domain by using Discrete Fourier Transform to calculate the required areas.

The proposed scheme can be used for the detection of out of step condition using equal area criterion with different types of faults at different locations and different models of transmission lines.

Keywords: Phasor Measurement Unit (PMU), Global positioning system (GPS), Transmission line protection, Power system transient stability, Discrete Fourier Transform (DFT), Equal-area criterion, Out of step detection.

* Department of Electrical Power \& Machines, Faculty of Engineering, Ain Shams University, Cairo, Egypt 


\section{$\underline{\text { 1. Introduction }}$}

Transmission line protection is the most elaborate and challenging function in power system protection. About two-thirds of faults in power systems occur on the transmission line network. Consequently, it has received extensive attention from researchers and designers in the area of power system protection $[1,2]$.

Today's power systems are interconnected networks of transmission lines linking generators and loads into large integrated systems, some of which span entire countries and even continents [3]. The main requirements for the reliable operation of such systems are to keep the synchronous generators running in parallel and with adequate capacity to meet the load demand. In power system stability studies the term transient stability usually refers to the ability of the synchronous machines to remain in synchronism during the brief period following a large disturbance, such as a short circuit on a bus [4]. In large disturbance system nonlinearities play a dominant role. In order to determine transient stability or instability following a large disturbance, or a series of disturbances, time-domain simulation (TDS) method is usually employed to solve the set of nonlinear equations describing the system dynamic. Conclusion about stability or instability can then be drawn from an inspection of the solution [5].

In the actual operation of an electric power system, the parameters and loading conditions are quite different from those assumed at the planning stage. As a result, to ensure power system transient stability against possible abnormal conditions due to contingences (disturbances), the system operator needs to simulate contingences in advance, assess the results, and take preventive control action if required. The TDS technique is the most accurate method for assessing the power system transient stability [6, 7]. The TDS approach can be applied to any level of detail of power system models and gives visual information about state variables. One of the main disadvantages of the TDS approach, except for being time-consuming, is that it does not provide information about the stability margin of the system [8].

The transient energy function (TEF) method [9, 10] and extended equal area criterion (EEAC) $[11,12]$ have also been applied in power system transient stability assessment. However, these methods have some modeling limitations and they still need a lot of computations to determine an index for transient stability analysis [13].

Artificial neural networks (ANNs) are gaining popularity in many engineering and scientific applications due to their high computation rates, ability to handle nonlinear functions and great degree of robustness. The prediction of out-of-step condition is a classification problem with two classes. A new approach to out-of-step prediction with the advantage of initiating early tripping for unstable swings while avoiding tripping on stable swings is presented in [14].

The technology of synchronized phasor measurements is well established. It provides an ideal measurement system for monitoring and controlling a power system, especially during stressed conditions. The essential feature of the technique is that it measures positive sequence (and negative and zero sequence quantities, if needed) voltages and currents of a power system in real time with precise time synchronization. This allows accurate comparison of measurements over widely separated locations as well as potential real-time 
measurement based control actions $[15,16]$. A new approach, considering synchronized measurement data from both ends of a transmission line, to protect transmission line is presented in [17].

This paper presents a transmission line protection scheme based on synchronized phasor measurement units to detect (predict) out of step condition. This scheme uses the measured values of voltages and currents, as complex values, at the generator bus and at the infinite bus. This scheme can be used for the detection of out of step condition using equal area criterion with different types of faults at different locations and different models of transmission lines.

\section{Phasor Measurement Unit}

The modern PMUs use one pulse per second signals provided by the Global positioning system (GPS) satellite receivers as shown in Figure 1.

The accuracy of the GPS timing pulse is better than $1 \mathrm{~s}$, which for a $60 \mathrm{~Hz}$ system corresponds to about 0.02 degrees, this accuracy is more than enough to ensure that the measurements obtained by such clocks will be simultaneous for the purpose of estimation and analysis of the power system state [18].

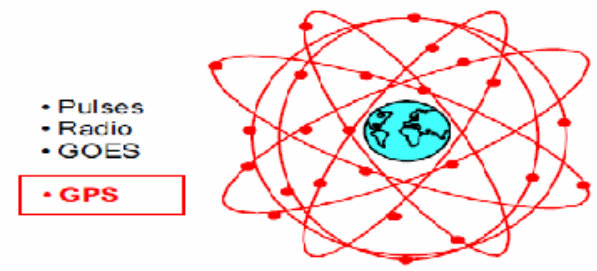

Figure 1: GPS satellite transmissions as the preferred method of achieving synchronization of sampling clocks in PMUs

\subsection{Measurements Techniques}

The basic definition of the phasor representation of a sinusoid is illustrated in Figure 2 . Assume a single frequency constant sinusoid of frequency $\omega$ is observed starting at time $t=$ 0 . The sinusoid can be represented by a complex number called 'Phasor' which has a magnitude equal to the root-mean-square (rms) value of the sinusoid, and whose angle is equal to the angle between the peak of the sinusoid and the $t=0$ axis.

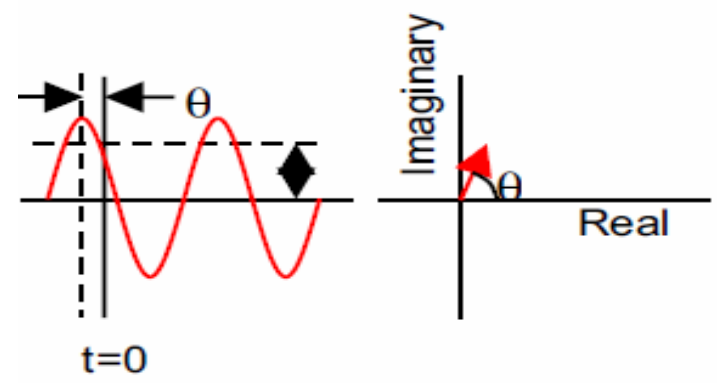

Figure 2: Definition of a Phasor, a complex number representation of a constant pure sinusoid. 
If the sinusoid is not a pure sine wave, the phasor is assumed to represent its fundamental frequency component calculated over the data window.

The most commonly used method of calculating phasors from sampled data is that of Discrete Fourier Transform (DFT) as shown in Figure 3. The sampling clocks are usually kept at a constant frequency even though the input signal frequency may vary by a small amount around its nominal value as described in [19].

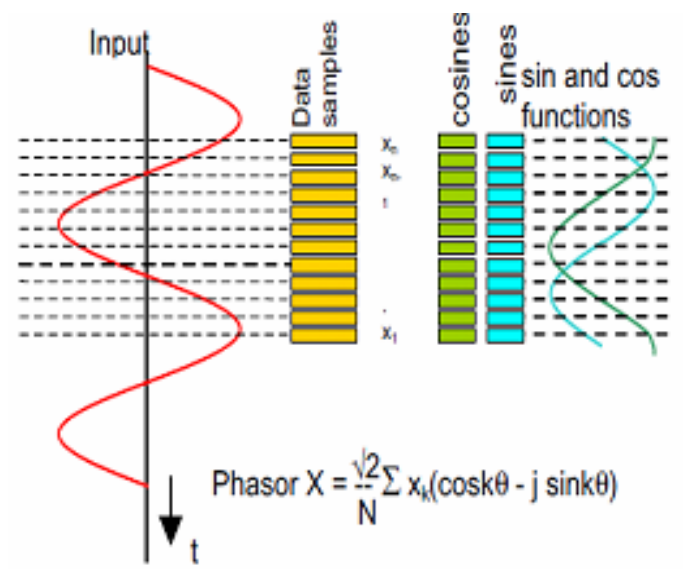

Figure 3: Estimation of phasors from sampled data using Discrete Fourier

Transform.

A more computationally efficient method is to compute the estimated phasor recursively by adding the contribution made by the new sample, and subtracting the contribution made by the oldest sample. This is illustrated in Figure 4. A useful artifact of the recursive DFT algorithm is that the constant sinusoid of nominal frequency produces a constant phasor [18].

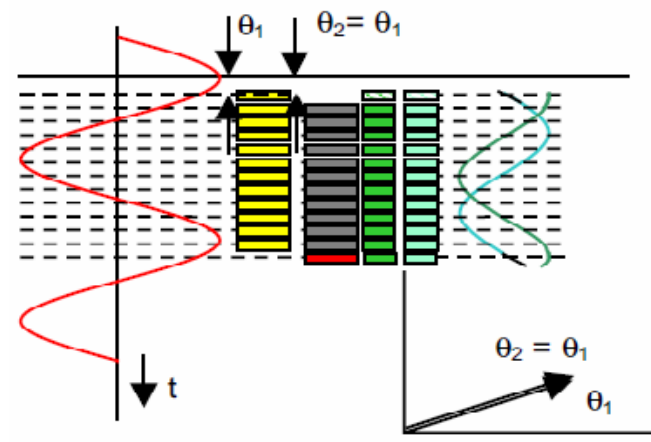

Figure 4: Recursive estimation of phasors from sampled data with moving window DFT.

A phase may be used as an indicator of the dynamic performance of a power system, as is well appreciated in the dynamic swing equations [20].

\section{Some Applications of PMUs in Power System}

\subsection{Advanced network protection}

This category of applications of synchronized phasor measurements is that of enhancing the effectiveness of power system protection. This involves equipment and 
system protection, as well as remedial action schemes. An example of phasor measurements used for protection is given in the adaptive out-of-step relaying study, using concepts from transient stability analysis; it is possible to design improved outof-step relays [21].

\section{$\underline{3.2 \text { Detection of Instability }}$}

Detection of instability in power systems is not a relaying function. However, many relaying functions (load shedding, for example) depend upon the premise that given the current state of a power system, it will remain stable following a transient oscillation. Conversely, the out-of-step tripping function is based upon, the premise that the post-disturbance system will be unstable. In a power system consisting of two synchronous machines and a connecting network over which synchronizing power can flow, the problem of instability detection can be solved in real-time. The equalarea criterion is applicable in this case, and if the machine rotor angles and speeds can be measured in real-time a prediction algorithm can be developed for the detection of instability [22].

\subsubsection{Phase as Indicator of the Dynamic Performance of a Power System}

Synchronous machines must adapt to different operating conditions when exchanging real power across a power system [23]. The machines accelerate or decelerate to adapt to changing power transfer requirements that occur during system disturbances. Power system dynamics involve the electrical properties, as well as the mechanical properties, of all the electrical machines in the system. For the purpose of this discussion, assume a two-pole synchronous machine where the mechanical and electrical degrees are equal.

The difference between shaft torque, $\mathrm{T}_{\mathrm{m}}$ and electromechanical torque, $\mathrm{T}_{\mathrm{e}}$, in a machine determines the accelerating torque, $\mathrm{T}_{\mathrm{a}}$, as shown by Equation (1). In generators, $\mathrm{T}_{\mathrm{a}}>0$ accelerates the machine.

$T_{a}=T_{m}-T_{e}$

We can represent power, $\mathrm{P}$, as a function of torque, $\mathrm{T}$, according to Equation (2).

$P=T . \omega$

Where,

$\mathrm{T}$ is the torque, N.m

$\omega$ is the angular velocity, $\mathrm{rad} / \mathrm{s}$

It can be seen from Equation (3); the change of the angular rotor position, $\theta$, with respect to time determines the angular velocity, $\omega$.

$\omega=\frac{d \theta}{d t}$

The torque, $\mathbf{T}$, is a function of the moment of inertia, $\mathbf{J}$, and the angular acceleration, $\alpha$, according to Equation (4).

$T=J . \alpha$

Where,

$\mathrm{J}$ is the moment of inertia, $\mathrm{kg} \cdot \mathrm{m}^{2}$ 
$\alpha$ is the change of the angular velocity with respect to time, $\mathrm{rad} / \mathrm{s}^{2}$

As in Equation (5), the angular momentum, $\mathbf{M}$, is a function of the moment of inertia, $\mathbf{J}$, and the angular velocity, $\omega$.

$M=J . \alpha$

With equation (6), we can represent the accelerating power, $\mathrm{P}_{\mathrm{a}}$, as a function of the angular acceleration, $\alpha$, and as a function of the angular rotor position, $\theta$.

$P_{a}=T_{a} \cdot \omega=M \cdot \alpha=M \cdot \frac{d^{2} \theta}{d t^{2}}$

The rotor angle position can be expressed with respect to a synchronous reference frame that rotates at synchronous speed, $\omega_{\text {syn. }}$ The angular rotor position, $\theta$, is equal to the phase angle due to the synchronous rotating reference, $\omega_{\text {syn }} . t$, plus the angular displacement from the synchronous rotating reference, $\delta$, as shown in Equation (7).

$\theta(t)=\omega_{s y n} . t+\delta$

The angular velocity, $\omega$, is:

$\omega=\frac{d \theta}{d t}=\omega_{s y n}+\frac{d \delta}{d t}$

Taking the derivative of the angular velocity, we can rewrite Equation (6) as a function of $\delta$ :

$P_{a}=M \frac{d^{2} \delta}{d t^{2}}$

We can express Equation (9) as a function of the constant inertia, $\mathbf{H}$, with power expressed in per unit as follows:

$P_{a}=P_{m}-P_{e}=\frac{2 H}{\omega_{s y n}} \frac{d \omega}{d t}$

Where,

$\mathrm{P}_{\mathrm{m}}$ is the mechanical power supplied to the generator, pu

$\mathrm{P}_{\mathrm{e}}$ is the electrical power supplied to the system, pu

$\mathrm{H}$ is the constant of inertia, $\mathrm{s}$

Equation (10) is known as the swing equation; one swing equation per machine is necessary to model the network dynamics. When the load-generation equation is balanced (total load equals total generation), machine speeds are practically equal to synchronous speed. The angular displacements, $\delta$, of machines in a system provide information about the system dynamics. One cannot measure this angular displacement mechanically. By computing the voltage phasor behind the machine transient reactance, one can study the phase angle variations to obtain an image of the machine angular displacement. In practice, machine-oscillating modes can be determined by measuring the phase angle of the positive-sequence voltage phasor at the machine terminals [20].

\subsubsection{Adaptive Out-Of-Step Protection}

It is recognized that a group of generators going out of step with the rest of the power system is often a precursor of a complete system collapse. Whether an 
electromechanical transient will lead to stable or unstable condition has to be determined reliably before appropriate control action could be taken to bring the power system to a viable steady state. Out-of-step relays are designed to perform this detection and also to take appropriate tripping and blocking decisions [24].

For single machine system or two machines system, Equal area criterion (EAC) is an effective method to assess power system stability. EAC has excellent characteristic, it inspires many scholars to apply EAC to multi-machines [25].

\section{Theory of Single Machine-Infinite Bus System}

\subsection{Power Transfer Equation}

For a simple lossless transmission line connecting a generator and infinite bus as shown in Figure 5.

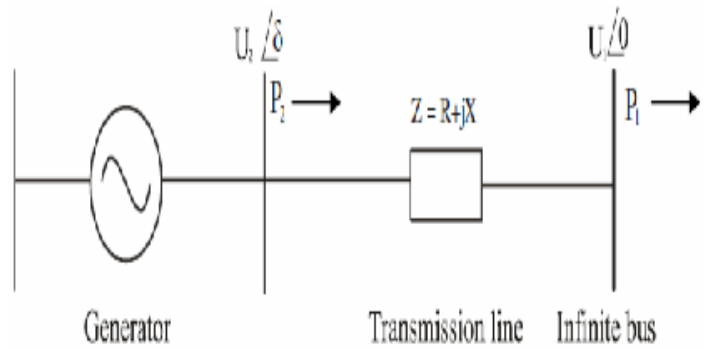

Figure 5: One machine against infinite bus diagram.

If $\mathrm{V}_{1}=\mathrm{V}_{2}=\mathrm{V}_{2} \cos \delta+\mathrm{j} \mathrm{V}_{2} \sin \delta$,

$\mathrm{Z}=\mathrm{R}+\mathrm{j} \mathrm{X}$

It is well known that the active power, $\mathrm{P}$, transferred between two generators for a lossless line can be expressed as:

$P=V_{1} \frac{V_{2}}{X} \cdot \sin \delta$

Where,

$\mathrm{V}_{1}$ is the voltage of the infinite bus (reference voltage), volt

$\mathrm{V}_{2}$ is the voltage of the generator bus, volt

$\delta$ is the angle difference between the generator and infinite bus, rad

$\mathrm{X}$ is the total reactance of the transmission line and generator.

The maximum amount of power that can be transferred over the line, $\mathrm{P}_{\max }$ when $\delta=$ 90 degree [26].

\subsection{The Power Angle Curve}

The generator in Figure 5 is in stable operation at a phase angle of $\delta$ compared to the infinite bus, i.e. the voltage at the generator bus U2 is leading the voltage at the infinite bus $\mathrm{U} 1$ by an angle $\delta$. The mechanical power input, Pm, and the electrical power output, $\mathrm{P}_{\mathrm{e}}$, drawn in Figure 6 describes the power balance of the generator. The 
curves intersect at two points, the stable equilibrium point and the unstable equilibrium point.

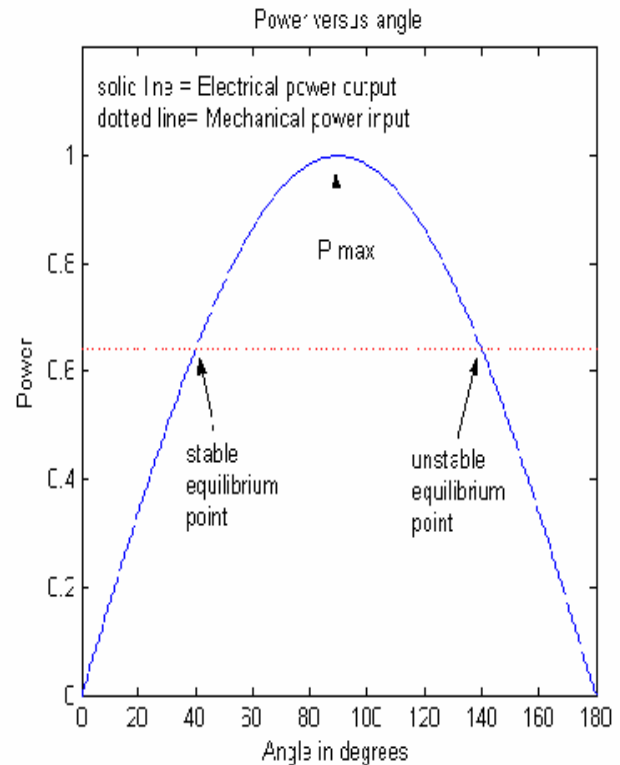

Figure 6: Input (dashed) and Output (solid) power of turbine generator.

\subsection{Transiently Stable and Unstable Systems}

In Figure 7 the changes of angle and power transfer between the generator and the infinite bus, before, during and after a fault, are plotted.

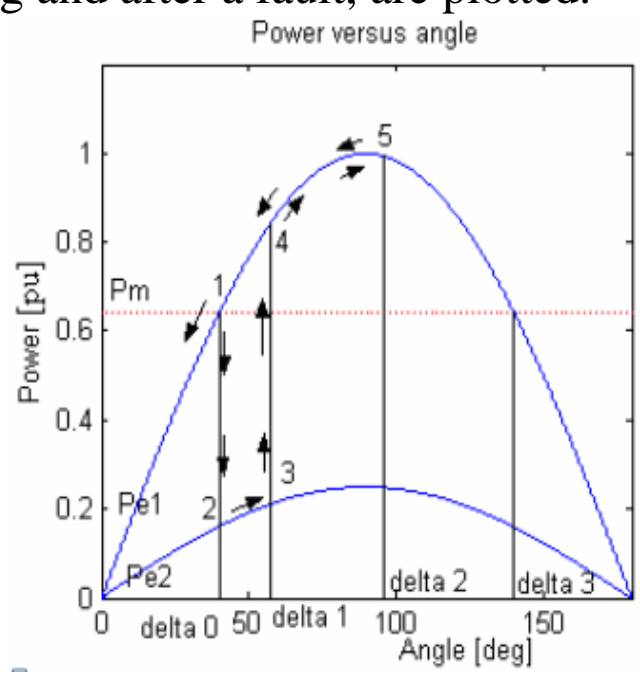

Figure 7: Power transfer before, during and after a fault close to the turbinegenerator.

\subsection{The Equal Area Criterion}

The equal-area criterion can be used to calculate the maximum fault clearing time before the generator loses synchronism. The equal-area criterion integrates the energy gained when the turbine-generator is accelerating, during the fault (area A, in Figure 8 ) and compares that area with the decelerating area, (area B, in Figure 8) when the generator exports the energy stored during the fault. 


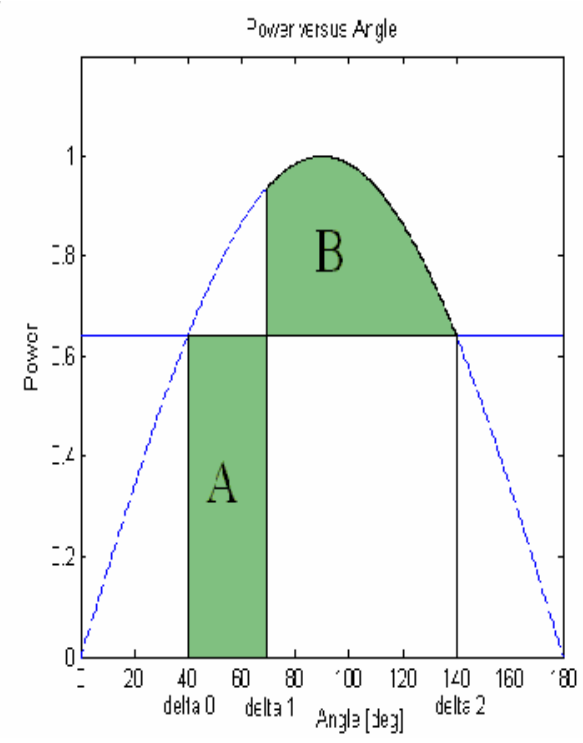

Figure 8: Equal-area criterion with an acceleration area $A$ and a decelerating area $B$.

Area A represents the total kinetic energy gained during the acceleration period. As soon as the fault is cleared, at angle $\boldsymbol{\delta} \mathbf{1}$, the angle will continue to increase and the kinetic energy gained during the fault period will expand into the power system.

When area $\mathbf{B}$ is equal to area $\mathbf{A}$ angle $\boldsymbol{\delta}$ has reached its maximum value [26].

$A=\int_{\delta_{o}}^{\delta_{1}}\left(P_{m}-P_{e, \text { fault }} \sin \delta\right) d \delta$

$B=\int_{\delta_{1}}^{\delta_{2}}\left(P_{e, \max } \sin \delta-P_{m}\right) d \delta$

When area $\mathrm{A}<\mathrm{B}$ the system will be stable and if $\mathrm{A}>\mathrm{B}$ the system will be unstable.

\section{Evaluation of the proposed protection scheme}

\subsection{Power system model}

Using the Electromagnetic Transient program PSCAD/EMTDC, a single machine, three-phase $400 \mathrm{kV}$ power system against infinite bus with a line of $900 \mathrm{~km}$ length divided into six identical $\pi$ sections each of length $150 \mathrm{~km}$ has been simulated for the analysis of the proposed protection scheme. The one-line diagram of the studied system is shown in Figure 9 and its parameters are shown in Table 1. The transmission line is a double-circuit line and simulated using both the Bergeron model and the frequency-dependent model options. 


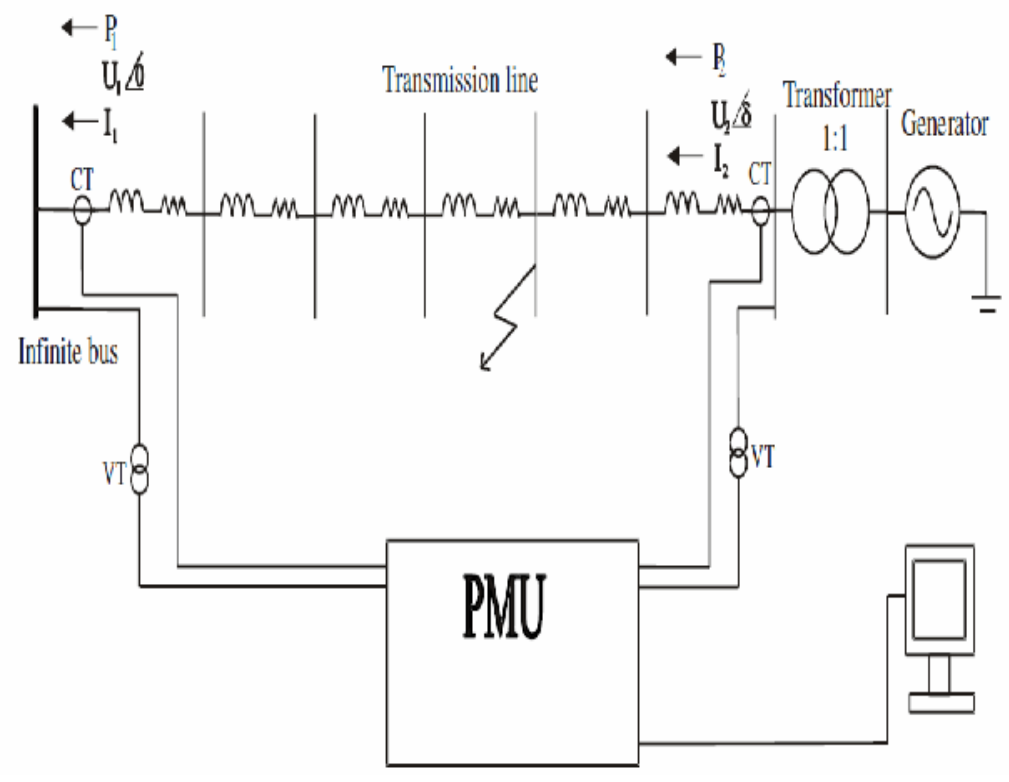

Figure 9: Simulated power system model.

Table 1: Simulated power system parameters

\begin{tabular}{|l|l|}
\hline Positive sequence resistance $\mathrm{R}$ & $2.925^{*} 10^{\wedge}-9 \mathrm{p} . \mathrm{u} / \mathrm{m}$ \\
\hline Positive sequence inductive reactance $\mathrm{X}_{\mathrm{L}}$ & $3.6225^{*} 10^{\wedge}-8 \mathrm{p} . \mathrm{u} / \mathrm{m}$ \\
\hline Positive sequence capacitive reactance $\mathrm{X}_{\mathrm{C}}$ & $0.571^{*} 10^{\wedge} 6 \mathrm{p} . \mathrm{u} / \mathrm{m}$ \\
\hline Zero sequence resistance $\mathrm{R}$ & $8.775^{*} 10^{\wedge}-9 \mathrm{p} . \mathrm{u} / \mathrm{m}$ \\
\hline Zero sequence inductive reactance $\mathrm{X}_{\mathrm{L}}$ & $1.08675^{*} 10^{\wedge}-7 \mathrm{p} . \mathrm{u} / \mathrm{m}$ \\
\hline Zero sequence capacitive reactance $\mathrm{X}_{\mathrm{C}}$ & $0.793^{*} 10^{\wedge} 6 \mathrm{p} . \mathrm{u} / \mathrm{m}$ \\
\hline
\end{tabular}

The performance of the proposed MATLAB program has been tested for different faults in a validation set with different fault types, fault locations.

\subsection{Out of Step Detection Algorithm}

Figure 10 shows a flow chart for the proposed out-of-step detection algorithm. First the algorithm takes data from the EMTDC/PSCAD program. This data will be converted by a DFT to complex phasors of voltages and currents. After that the program determines the areas A and B and finally checks if there is out-of-step condition or not.

Different types of faults are applied to the system in the transmission line near to the generator bus, as a fault at a bus near the infinite bus will cause very high fault current and will not be possible to measure. 


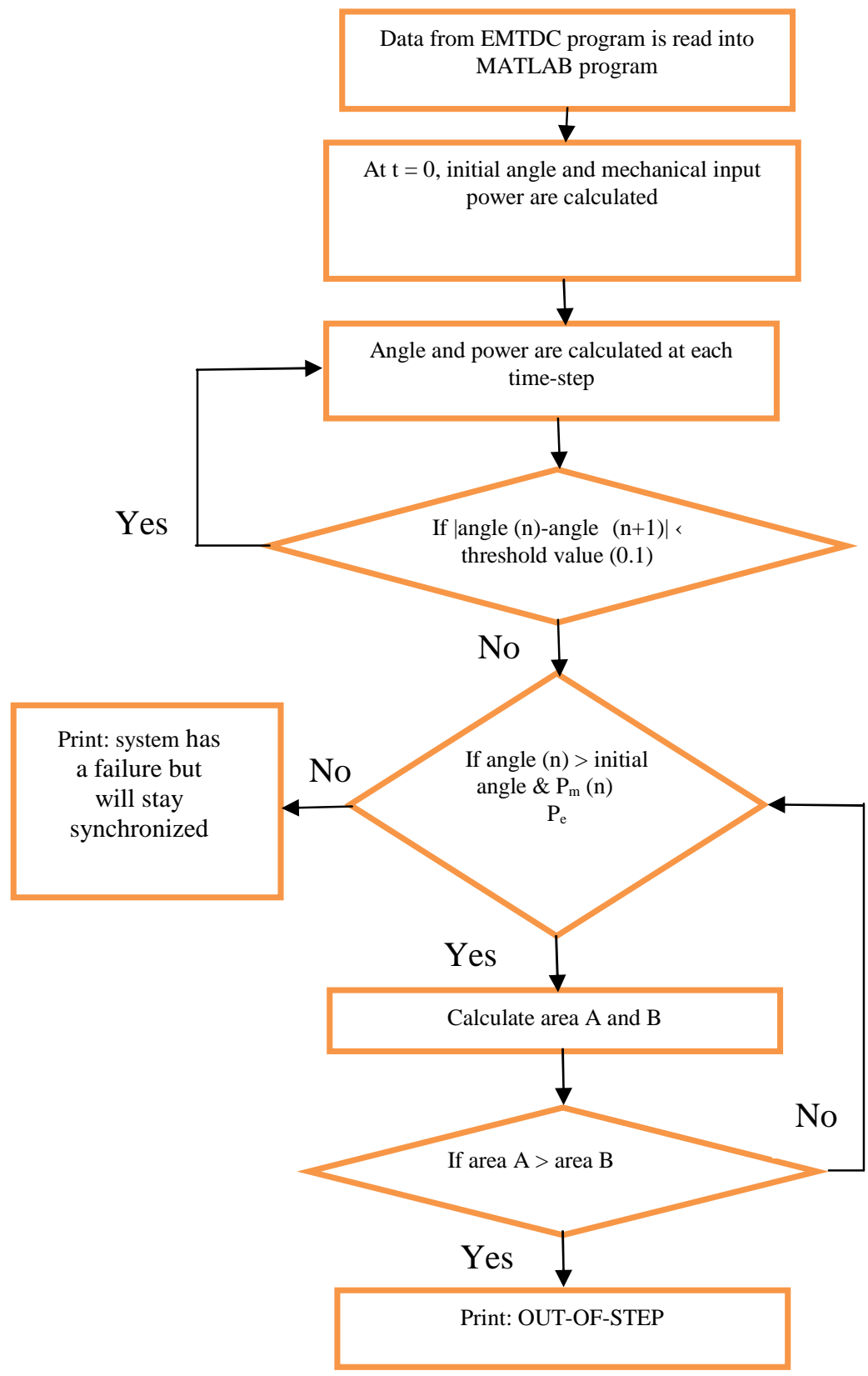

Figure 10: Flowchart of algorithm

\subsection{Simulation Results}

Some test results are presented in the following subsections.

\subsubsection{Case 1: 3-phase short circuit at $300 \mathrm{~km}$ from generator side using Bergeron}

\section{Model}

Time of fault: $0.4 \mathrm{sec}$.

Duration of fault: $0.05 \mathrm{sec}$.

Transmission line: Bergeron model options, manual entry of admittance $Y$, impedance Z. 
Figures 11, 12, 13 and 14 show voltage and current waveforms at both sides (generator bus and infinite bus) obtained from the simulation using the PSCAD/EMTDC program.

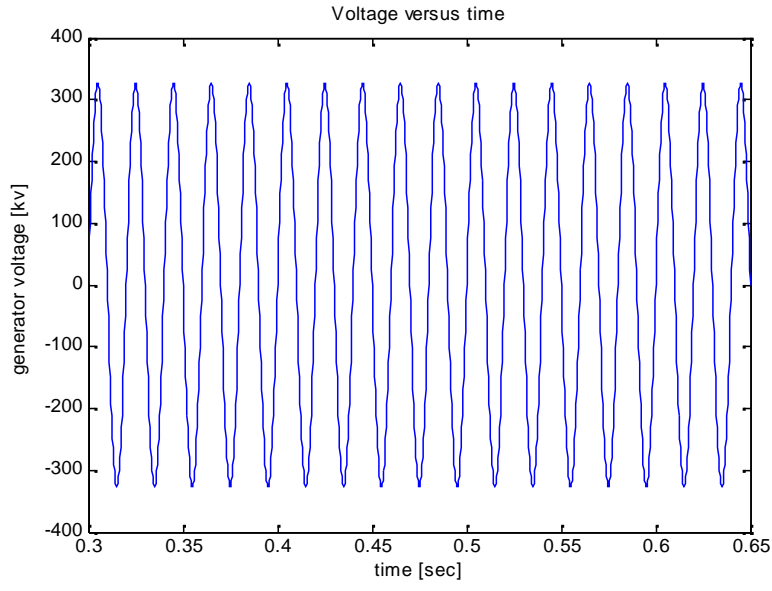

Figure 11: voltage at generator bus.

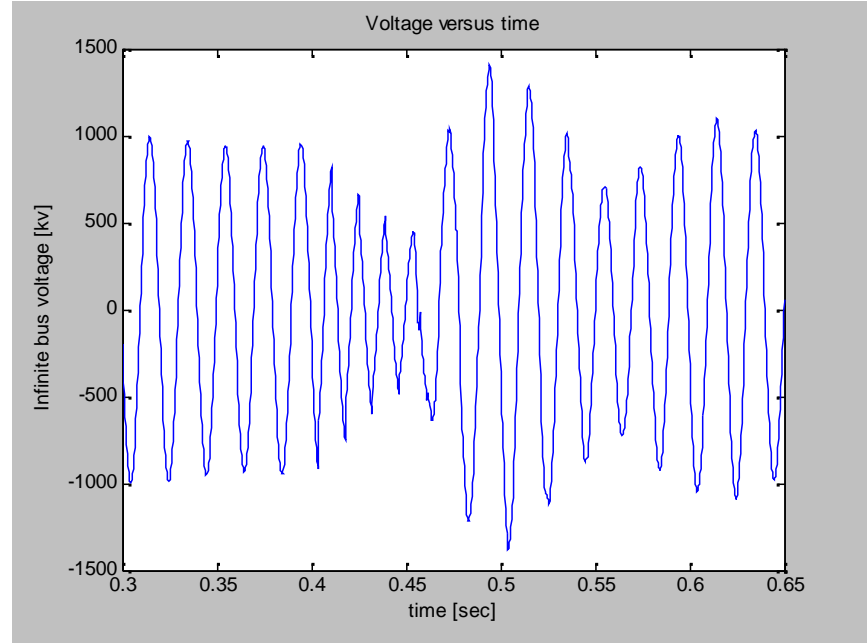

Figure 12: voltage at infinite bus.

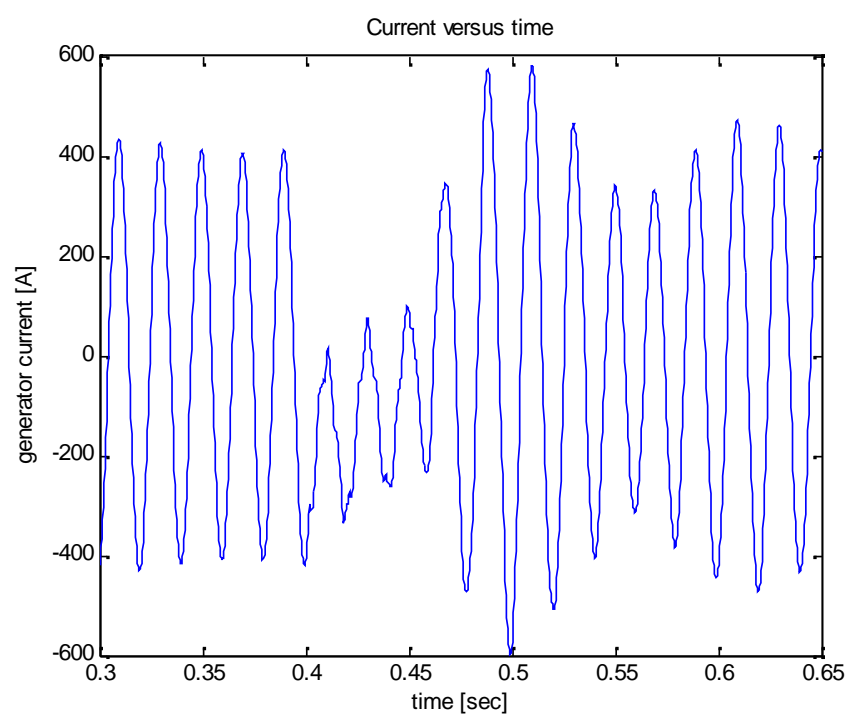

Figure 13: current at generator bus. 


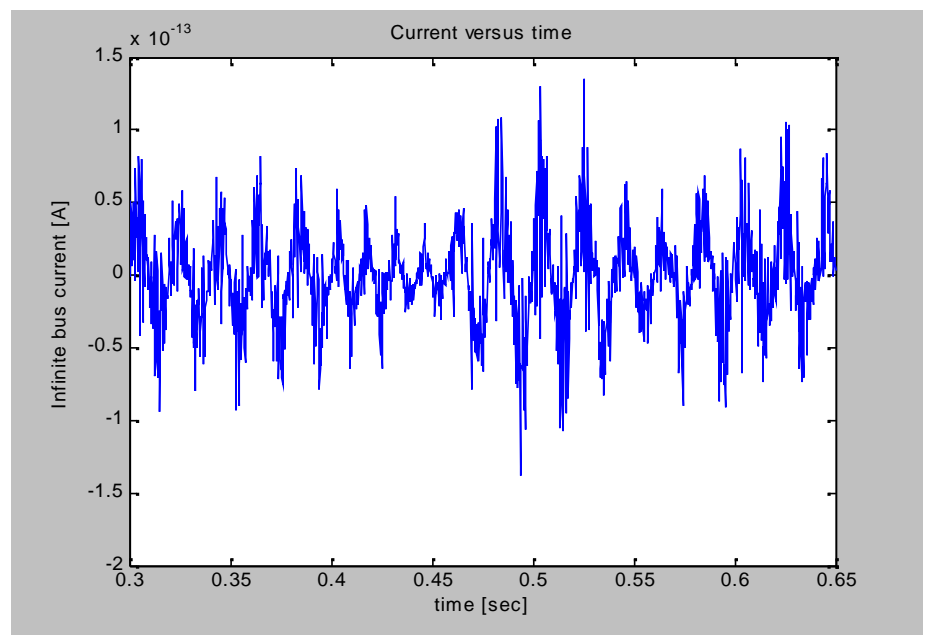

Figure 14: current at infinite bus.

The proposed scheme is tested for calculating areas A and B for this fault and determines if the generator will be out of step (unstable condition) or not.

\subsubsection{Case 2: 3-phase short circuit at $300 \mathrm{~km}$ from generator side using frequency-}

\section{dependent model}

Time of fault: $0.3 \mathrm{sec}$.

Duration of fault: $0.15 \mathrm{sec}$.

Transmission line: frequency-dependent model.

Figures 15, 16, 17 and 18 show voltage and current waveforms at both sides (generator bus and infinite bus) obtained from the simulation using the PSCAD/EMTDC program.

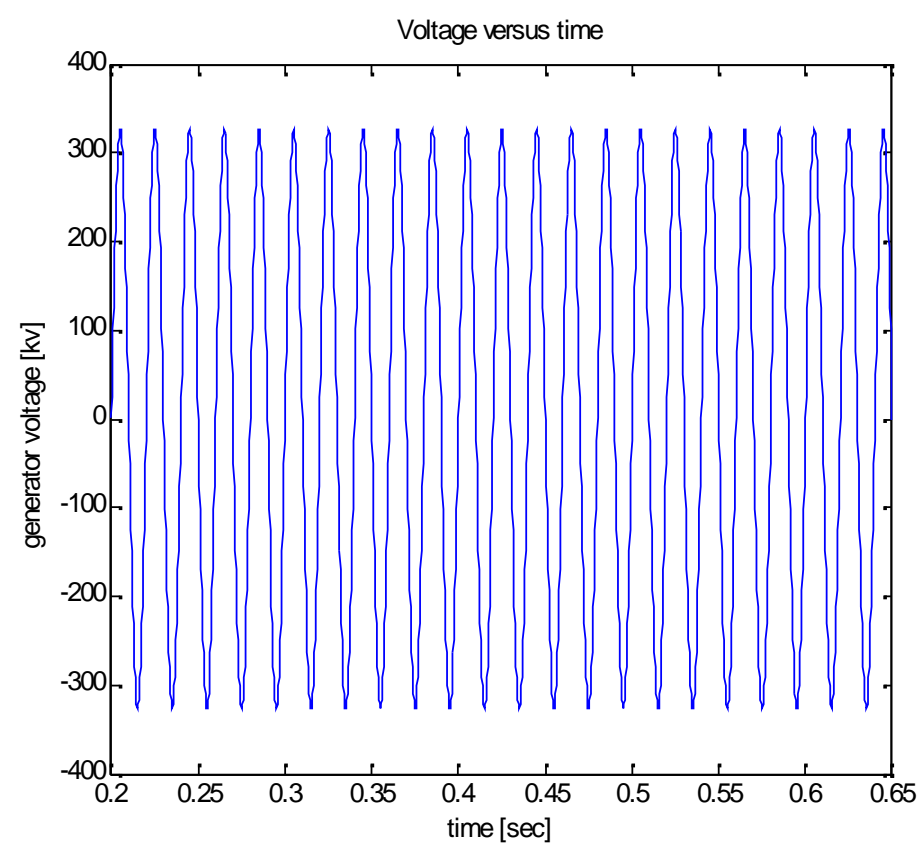

Figure 15: voltage at generator bus. 
Proceedings of the $\boldsymbol{8}^{\text {th }}$ ICEENG Conference, 29-31 May, 2012

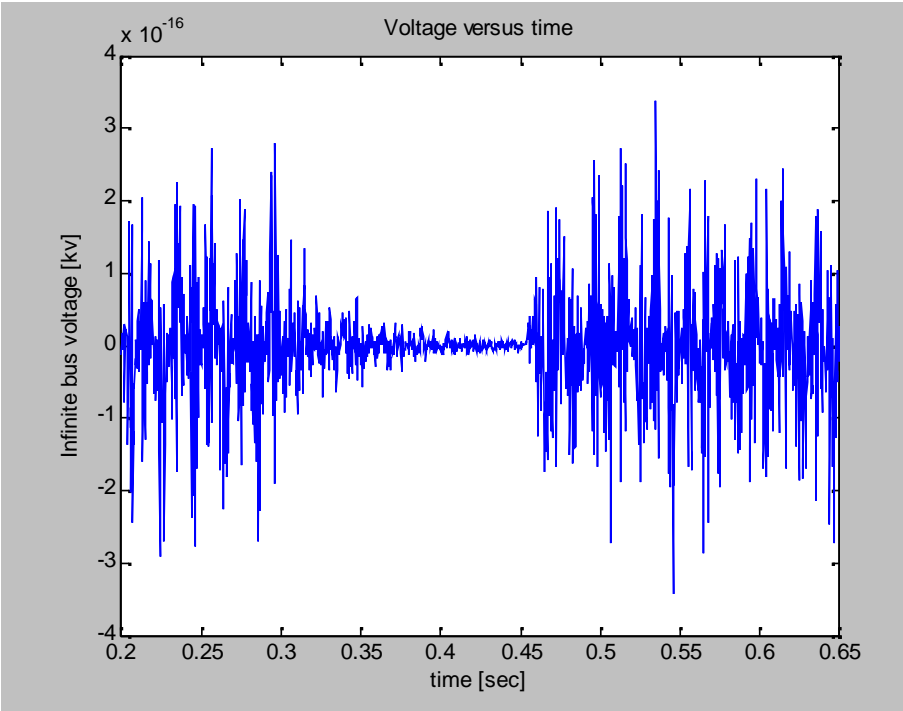

Figure 16: voltage at infinite bus.

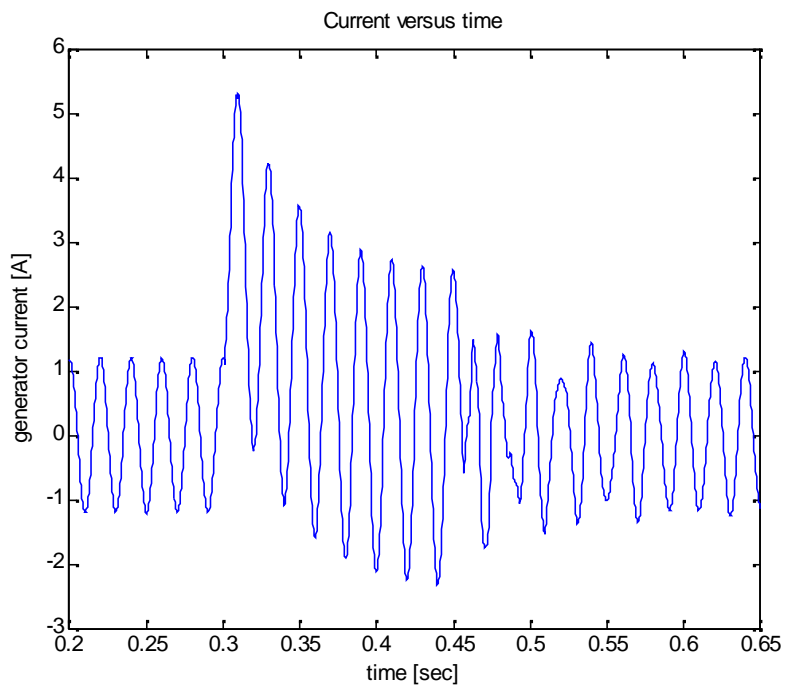

Figure 17: current at generator bus.

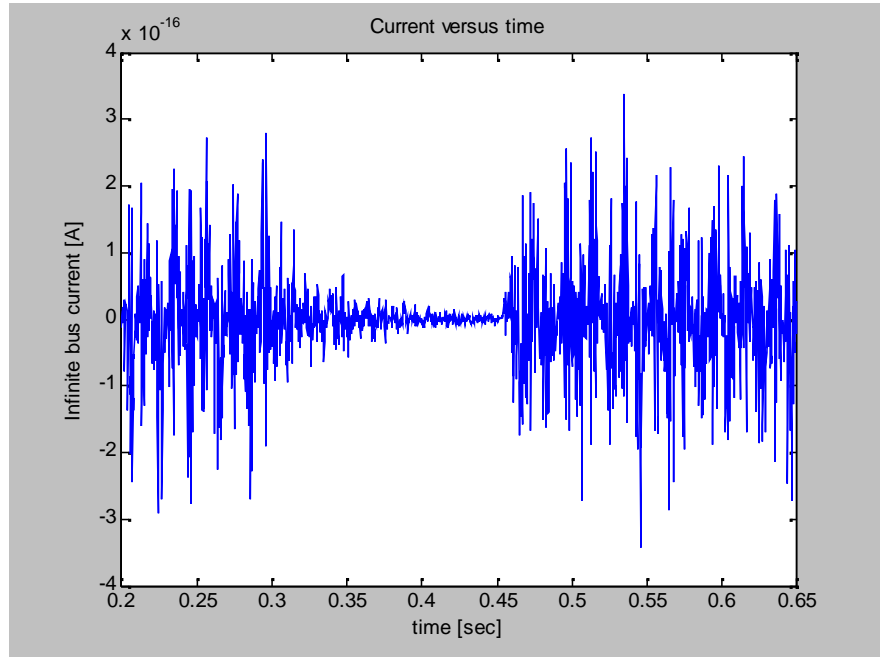

Figure 18: current at infinite bus. 
The proposed scheme is tested for calculating areas A and B for this fault and determines if the system has had a failure but will not lose a synchronism (stable condition) or not.

\subsubsection{Scheme responses to different faults}

The proposed scheme is tested for detecting the system stability. The program output for different faults at different locations with different models of transmission line is shown in Table 2. Also, the effect of variation of the fault inception time and duration for a fault occurring at a certain distance is given in Table 3 .

It is concluded from Table 2 that time of fault inception is directly related to the angle difference between the generator and infinite bus $(\delta)$ which will affect the accelerating and decelerating area and will affect the stability of the system. Also, for faults near the infinite bus, this will cause very high fault currents which will cause instability. For the same values of fault inception time and duration, faults at lengths $600 \mathrm{~km}$ and $750 \mathrm{~km}$ will cause instability while faults at 150, 300 and $450 \mathrm{~km}$ are stable. For the three phase short circuit faults, the results obtained by the proposed scheme are compared with the actual values found by the step-by-step method and the results are identical.

Table 2: Test results of the proposed scheme to different faults at different locations of the transmission line

\begin{tabular}{|l|l|l|l|l|}
\hline $\begin{array}{l}\text { Fault } \\
\text { location }\end{array}$ & Fault type & $\mathrm{t}_{\mathrm{f}}$ & $\mathrm{D}_{\mathrm{f}}$ & $\begin{array}{l}\text { Proposed } \\
\text { Scheme Output }\end{array}$ \\
\hline $150 \mathrm{~km}$ & AG & 0.2 & 0.05 & stable \\
\hline $150 \mathrm{~km}$ & AG & 0.3 & 0.05 & unstable \\
\hline $150 \mathrm{~km}$ & BG & 0.3 & 0.05 & unstable \\
\hline $150 \mathrm{~km}$ & CG & 0.3 & 0.05 & unstable \\
\hline $150 \mathrm{~km}$ & BC & 0.2 & 0.05 & stable \\
\hline $150 \mathrm{~km}$ & AB & 0.3 & 0.1 & unstable \\
\hline $150 \mathrm{~km}$ & BC & 0.3 & 0.1 & unstable \\
\hline $150 \mathrm{~km}$ & CA & 0.3 & 0.1 & unstable \\
\hline $150 \mathrm{~km}$ & CAG & 0.2 & 0.05 & stable \\
\hline $150 \mathrm{~km}$ & ABG & 0.4 & 0.05 & unstable \\
\hline $150 \mathrm{~km}$ & BCG & 0.4 & 0.05 & unstable \\
\hline $150 \mathrm{~km}$ & CAG & 0.4 & 0.05 & unstable \\
\hline $150 \mathrm{~km}$ & ABCG & 0.3 & 0.05 & unstable \\
\hline $300 \mathrm{~km}$ & AG & 0.2 & 0.05 & stable \\
\hline $300 \mathrm{~km}$ & AG & 0.3 & 0.05 & unstable \\
\hline $300 \mathrm{~km}$ & BG & 0.3 & 0.05 & unstable \\
\hline $300 \mathrm{~km}$ & CG & 0.3 & 0.05 & unstable \\
\hline $300 \mathrm{~km}$ & BC & 0.2 & 0.05 & stable \\
\hline $300 \mathrm{~km}$ & AB & 0.3 & 0.1 & unstable \\
\hline
\end{tabular}


Proceedings of the $\boldsymbol{8}^{\text {th }}$ ICEENG Conference, 29-31 May, 2012

\begin{tabular}{|l|l|l|l|l|}
\hline $300 \mathrm{~km}$ & BC & 0.3 & 0.1 & unstable \\
\hline $300 \mathrm{~km}$ & CA & 0.3 & 0.1 & unstable \\
\hline $300 \mathrm{~km}$ & CAG & 0.2 & 0.05 & stable \\
\hline $300 \mathrm{~km}$ & ABG & 0.4 & 0.05 & unstable \\
\hline $300 \mathrm{~km}$ & BCG & 0.4 & 0.05 & unstable \\
\hline $300 \mathrm{~km}$ & CAG & 0.4 & 0.05 & unstable \\
\hline $300 \mathrm{~km}$ & ABCG & 0.3 & 0.05 & unstable \\
\hline $450 \mathrm{~km}$ & AG & 0.2 & 0.05 & stable \\
\hline $450 \mathrm{~km}$ & AG & 0.3 & 0.05 & unstable \\
\hline $450 \mathrm{~km}$ & BG & 0.3 & 0.05 & unstable \\
\hline $450 \mathrm{~km}$ & CG & 0.3 & 0.05 & unstable \\
\hline $450 \mathrm{~km}$ & BC & 0.2 & 0.05 & stable \\
\hline $450 \mathrm{~km}$ & AB & 0.3 & 0.1 & unstable \\
\hline $450 \mathrm{~km}$ & BC & 0.3 & 0.1 & unstable \\
\hline $450 \mathrm{~km}$ & CA & 0.3 & 0.1 & unstable \\
\hline $450 \mathrm{~km}$ & CAG & 0.2 & 0.05 & stable \\
\hline $450 \mathrm{~km}$ & ABG & 0.4 & 0.05 & unstable \\
\hline $450 \mathrm{~km}$ & BCG & 0.4 & 0.05 & unstable \\
\hline $450 \mathrm{~km}$ & CAG & 0.4 & 0.05 & unstable \\
\hline $450 \mathrm{~km}$ & ABCG & 0.3 & 0.05 & unstable \\
\hline $600 \mathrm{~km}$ & AG & 0.2 & 0.05 & unstable \\
\hline $600 \mathrm{~km}$ & BC & 0.2 & 0.05 & unstable \\
\hline $600 \mathrm{~km}$ & CAG & 0.2 & 0.05 & unstable \\
\hline $750 \mathrm{~km}$ & AG & 0.2 & 0.05 & unstable \\
\hline $750 \mathrm{~km}$ & BC & 0.2 & 0.05 & unstable \\
\hline $750 \mathrm{~km}$ & CAG & 0.2 & 0.05 & unstable \\
\hline
\end{tabular}

Where,

$t_{\mathrm{f}}$ is the time of fault inception.

$\mathrm{D}_{\mathrm{f}}$ is the duration of fault.

Table 3: Test results of the proposed scheme to faults at different fault inception times and different fault durations

\begin{tabular}{|l|l|l|l|l|}
\hline Fault location & Fault type & $\mathrm{t}_{\mathrm{f}}$ & $\mathrm{D}_{\mathrm{f}}$ & $\begin{array}{l}\text { Proposed Scheme } \\
\text { Output }\end{array}$ \\
\hline $300 \mathrm{~km}$ & AG & 0.1 & 0.1 & stable \\
\hline $300 \mathrm{~km}$ & AG & 0.2 & 0.05 & stable \\
\hline $300 \mathrm{~km}$ & AG & 0.2 & 0.2 & unstable \\
\hline $300 \mathrm{~km}$ & AG & 0.3 & 0.05 & unstable \\
\hline $300 \mathrm{~km}$ & AG & 0.4 & 0.1 & unstable \\
\hline $300 \mathrm{~km}$ & BC & 0.1 & 0.1 & stable \\
\hline $300 \mathrm{~km}$ & BC & 0.2 & 0.05 & stable \\
\hline
\end{tabular}




\begin{tabular}{|l|l|l|l|l|}
\hline $300 \mathrm{~km}$ & BC & 0.2 & 0.2 & unstable \\
\hline $300 \mathrm{~km}$ & BC & 0.3 & 0.05 & unstable \\
\hline $300 \mathrm{~km}$ & BC & 0.4 & 0.1 & unstable \\
\hline $300 \mathrm{~km}$ & CAG & 0.1 & 0.1 & stable \\
\hline $300 \mathrm{~km}$ & CAG & 0.2 & 0.05 & stable \\
\hline $300 \mathrm{~km}$ & CAG & 0.2 & 0.2 & unstable \\
\hline $300 \mathrm{~km}$ & CAG & 0.3 & 0.05 & unstable \\
\hline $300 \mathrm{~km}$ & CAG & 0.4 & 0.1 & unstable \\
\hline $300 \mathrm{~km}$ & ABCG & 0.1 & 0.1 & unstable \\
\hline $300 \mathrm{~km}$ & ABCG & 0.2 & 0.05 & unstable \\
\hline $300 \mathrm{~km}$ & ABCG & 0.2 & 0.2 & unstable \\
\hline $300 \mathrm{~km}$ & ABCG & 0.3 & 0.05 & unstable \\
\hline $300 \mathrm{~km}$ & ABCG & 0.4 & 0.1 & unstable \\
\hline
\end{tabular}

It is concluded from Table 3 that duration of fault is directly related to the angle of fault clearing which will affect the accelerating and decelerating area and will affect the stability of the system, when $\mathrm{D}_{\mathrm{f}}$ increases the system will tend to be unstable for the same $t_{\mathrm{f}}$.

\section{Conclusions}

This paper presents a transmission line protection scheme based on synchronized phasor measurement to detect out-of-step condition. The proposed scheme is applicable to the protection of double-circuit transmission lines as well as regular single-circuit line.

The Discrete Fourier Transform is used to transform the sampled data in phasor domain which is equivalent to PMU readings. The equal-area criterion is used and proved that it is an efficient method for determining the transient stability of a power system and detecting the out of step condition. Test results show that the proposed scheme is able to detect the out of step condition under different conditions with different fault types, different locations and different models of transmission line.

\section{References:}

[1] M. Sachdev, "Advancements in microprocessor-based protection and communication", IEEE Tutorial Course Text, Publication No. 97TP120-0, 1997.

[2] "Electricity Training Association", Power System Protection, Vol. 2, Digital Protection and Signaling, IEE, London, 1995.

[3] L. L. Grigsby, "Power system stability and control", CRC Press, 2007.

[4] "Definition and classification of power system stability", IEEE/CIGRE Joint Task Force, IEEE Transactions on Power Systems, August 2004, Vol. 19, No. 3, pp. 13871401.

[5] A. L. Bettiol, A. Souza, J. L. Todesco and J. R. Jr. Tesch, "Estimation of critical clearing times using neural network", IEEE Bologna power tech conference, Bologna, Italy, Vol. 3, 2003. 
[6] P. Kundur, "Power system stability and control", McGraw-Hill, 1994.

[7] M. Pavella and P. G. Murthy, "Transient stability of power systems: theory and Practice", John Wiley and Sons, 1994.

[8] A. Karami, "Power system transient stability margin estimation using neural networks", International Journal of Electrical Power and Energy Systems, Vol. 33, No. 4, May 2011, pp. 983-991.

[9] M. A. Pai, "Energy function analysis for power system stability", Springer, 1989. [10] A. A. Fouad and V. Vittal, "Power system transient stability analysis using the transient energy function method", Prentice-Hall, 1992.

[11] Y. Xue, T. V. Cutsem and M. A. Pavella, "Extended equal area criterion justifications, generalizations, applications", IEEE Transactions on Power Systems, 1989, Vol. 4, No. 1, pp. 44-52.

[12] Y. Xue, T. V. Cutsem and M. A. Pavella, "simple direct method for fast transient stability assessment of large power systems", IEEE Transactions on Power Systems, Vol. 3, No. 2, 1988, pp. 400-412.

[13] L. D. Colvara, "Stability analysis of power systems described with detailed models by automatic method", International Journal of Electrical Power and Energy Systems, Vol. 31, No. 4, May 2009, pp. 139-145.

[14] A. Y. Abdelaziz, M .R. Irving, A. M. El-Arabaty and M. M. Mansour, "Out-OfStep prediction based on artificial neural networks", Electric Power Systems Research, Vol. 34, No. 2, August 1995, pp. 135-142.

[16] S. Horowitz, A. Phadke, "Power System Relaying", 2nd ed., Research Studies/ Wiley, New York, 1995.

[17] A. Phadke, "Synchronized phasor measurements in power systems", IEEE Computer Applications in Power, Vol. 6, No. 2, 1993, pp. 10-15.

[18] H. K. Zadeha and Z. Li, "Phasor measurement unit based transmission line protection scheme design", Electric Power Systems Research, Vol. 81, No. 2, February 2011, pp. 421-429.

[19] A. G. Phadke and J. S. Thorp, "History and Applications of Phasor Measurements", Virginia Tech, Blacksburg, Virginia, USA, PSCE 2006.

[20] A. G. Phadke, J. S. Thorp, 2 chapters from "Advances in Electric Power and Energy Conversion System Dynamics and Control", edited by C. T. Leondes .

[21] Gabriel Benmouyal, E. O. Schweitzer and A. Guzmán, "Synchronized Phasor Measurement in Protective Relays for Protection, Control, and Analysis of Electric Power Systems", $57^{\text {th }}$ Annual Conference for Protective Relay Engineers, April 2004, pp. 419-450.

[22] David G. Hart, David Uy, Vasudev Gharpure, Damir Novosel, Daniel Karlsson and Mehmet Kaba, "PMUs- A new Approach to Power Network Monitoring", ABB Review1/2001.

[23] J. S. Thorp, A. G. Phadke, S. H. Horowitz and M. M. Ekgovic, "Some Applications of Phasor Measurements to Adaptive Protection", IEEE Transactions on Power Systems, Vol. 3, No. 2, May 1988, pp. 791-798.

[24] W. D. Stevenson, Jr., "Elements of Power System Analysis", $4^{\text {th }}$ Edition, McGraw-Hill Book Company, 1986. 
[25] Jaime De La Ree, Virgilio Centeno, James S. Thorp and A. G. Phadke, "Synchronized Phasor Measurement Applications in Power Systems", IEEE Transactions on Smart Grid, Vol. 1, No. 1, June 2010, pp. 20-27.

[26] L. Fang and Y. Ji-lai, "Transient Stability Analysis with Equal Area Criterion Directly Used to a Non- Equivalent Generator Pair", International Conference on Power Engineering, Energy and Electric Drives, Lisbon, Portugal, March 2009, pp. 386-389.

[27] A. H. Berkestedt, "Phasor Measurement based Out-Of-Step Detection", M. Sc. Thesis, Division of Electric Power Engineering, Department of Energy and Environment, Chalmers University of Technology, Göteborg, Sweden, 2007.

\section{Nomenclatures:}

$\theta$... Angular rotor position

$\omega$... Angular velocity

$\alpha$... Angular acceleration

M ... The angular momentum

A ... Accelerating area

B ... Decelerating area 